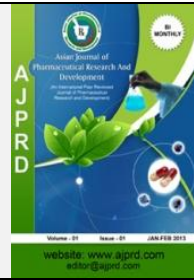

\title{
Fabrication and Characterization of Pluronic F68 and Phospholipon 90g Embedded Nanoformulation for Sertraline Delivery: An Optimized Factorial Design Approach and In Vivo Study
}

\author{
Kushwaha Krishna ${ }^{*}$, Mishra Manoj Kumar², Srivastava Rajat ${ }^{2}$
}

${ }^{1}$ Lutawan Institute of Pharmacy, Sakara Jaitpura, Ghazipur, Uttar Pradesh, India-233001

2 Department of Pharmaceutics, Shambhunath Institute of Pharmacy, Jhalwa, Prayagraj-

India, 211012

\begin{abstract}
A B S T R A C T
Objective: The objective of present work was to utilize the potential of nanostructured lipid carriers (NLCs) form improvement in bioavailability of Sertraline as antidepressant drug formulated by emulsification- solvent evaporation technique with some modification. NLC is the blend of solid lipid, liquid lipid and surfactant for encapsulation of poor water soluble actives. Design: A full $3^{2}$ factorial design was utilized to study the effect of two independent parameters namely solid lipid to liquid lipid concentration and stabilizer concentration on the entrapment efficiency of the prepared NLCs. The sertraline NLC formulation was characterized with respect to particle size, polydispersity index (PDI), zeta-potential, encapsulation efficiency and physical morphology. Result: The NLC formulation had an average diameter of $96.59 \mathrm{~nm}$, PDI of 0.192, zeta-potential of $39.88 \mathrm{mV}$, and encapsulation efficiency of $97 \%$, respectively. Conclusion: The NLC formulation for sertraline encapsulation has been successfully developed and is suitable for nose to brain delivery system due to their nano-size and stability.
\end{abstract}

Keywords: Sertraline, $3^{2}$ Factorial designs, Physical morphology, Nanostructure lipid carrier, Bioavailability, in vivo study

A R T I C L E I N F 0: Received 11 April 2019; Review Completed 20 May 2019; Accepted 29 May 2019; Available online 15 June 2019

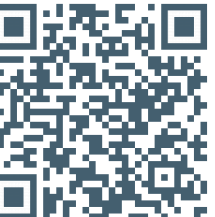

Cite this article as:

Kushwaha K, Mishra M K, Srivastava R, Fabrication and Characterization of Pluronic F68 and Phospholipon 90 g Embedded Nano formulation for Sertraline Delivery: an Optimized Factorial Design Approach and in Vivo Study, Asian Journal of Pharmaceutical Research and Development. 2019; 7(3):59-66, DOI: http://dx.doi.org/10.22270/ajprd.v7i3.505

Address for Correspondence:

Krishna Kushwaha, Lutawan Institute of Pharmacy, Sakara Jaitpura, Ghazipur, Uttar Pradesh, India

\section{INTRODUCTION}

$\mathrm{D}$ epression is one of the most common psychiatric disorders and is characterized by feelings of intense sadness, helplessness, worthlessness, and impaired functioning. Sertraline, an antidepressant drug ${ }^{1 \text {, }}$ 2 is a selective serotonin reuptake inhibitor (SSRI) administered orally alone or in combination with hydrochloride in a daily oral dose of $50 \mathrm{mg}$. But various problems are associated with its oral delivery such as extensive first-pass metabolism, gastrointestinal disturbances such as nausea, dry mouth, diarrhea, decreased appetite etc., and ultimately its poor bioavailability (40-45\%), which required this drug to be taken in high doses in order to maintain adequate plasma levels ${ }^{3}$.

NLCs second generation nanoparticles are unstructured solid lipid matrix made up of solid lipid, aqueous phase with surfactant ${ }^{4}$ and spatially incompatible liquid lipid which provides better drug loading and improved drug release of poorly water soluble drugs in comparison to SLNs. SLNs are blend of solid lipid and forms organized

ISSN: 2320-4850 crystal lattice which leads to drug expulsion of drug as at the time of production drug crystallizes in higher energy modification but after storage it transforms into lower energy ${ }^{5}$. NLCs have ability to incorporate large quantities of the drug due to imperfect crystal lattice it results in reduced burst release or drug expulsion, reduces the problems associated with solid lipid nanoparticles. They may increase the bioavailability, stability and shelf life of the drug. It provides food safety, nutritional value and controlled release of the encapsulated drugs. Liquid lipid added to NLCs results in lowers melting point and so maintains its character as it remains solid at body temperature with reduced burst release of the drug the ratio of solid lipid and liquid lipid ranges from 70:30 to 999.9: 0.1. Nasal crater as a noninvasive route provides self administration of the drug and leads to improved patient compliance and cost effective drug delivery system as it follows the transport of the drug direct through olfactory bulb and by absorption of the drug into blood and follows crossing of blood brain barrier ${ }^{6}$. NLCs for intranasal administration considered as attractive approach for the drugs having short half life and poor 
ability to cross BBB ${ }^{7}$.Diameter of NLCs ranging from 10-1000 nm. Advantages of NLC s are high biocompatibility, controlled drug release, improved bioavailability of drugs and the possibility of large industrial scale production ${ }^{8}$.

For poorly soluble compounds are unique solution is to incorporate the drug in lipids ${ }^{9}$. Sertraline, having poor solubility and bioavailability $(40-45 \%)$ is a selective serotonin reuptake inhibitor undergoes extensive first pass metabolism so for maintaining adequate plasma level drug should be taken in high doses Sertraline inhibits the serotonin uptake in presynaptic terminal. It depresses the firing of neurons in raphe nucleus ${ }^{10}$. NLC are particles produced from the blend of solid and liquid (oil) lipids and possesses many "imperfections" which increases drug loading capacity and minimizes or avoids drug expulsion during storage ${ }^{11}$. NLC are colloidal carriers characterized by a solid lipid core consisting of a mixture of solid and liquid lipids, and having a mean particle size in the nanometre range. Their lipophilic features facilitate crossing the $\mathrm{BBB}$ to enter the brain by endocytosis. Several drugs have been incorporated into lipid NPs (NLCs), which are potentially useful for the treatment of brain diseases ${ }^{12}$. A noninvasive technique for drug delivery to the brain is through intranasal administration, was shown to present a safe and acceptable alternative to parenteral administration of various drugs that offers rapid absorption to the systemic blood, avoiding first-pass metabolism in the gut wall and the liver .Nasal crater is a well tolerated and non-invasive route with ease of administration. Nasal delivery provides self administration and dosage control when required which facilitate home treatment and a cost-effective substitute. Systemic delivery of drugs acting on central nervous system (CNS), such as antidepressants, is considerably complicated due to the discriminatory physiological barriers that selectively seize the CNS from the circulatory system.

\section{MATERIALS AND METHODS}

\section{Materials}

The following materials were used from the indicated sources, without further purification. Sertraline was procured as a gift sample from Cipla Ltd., Sikkim, India. Cetyl palmitates, stearic acid, pluronic F68, dialysis membrane 70 were purchased from Himedia, Mumbai, India. Phospholipon 90G (phosphotidylcholine 30\%) was kindly gifted by $\mathrm{GmbH}$, Germany. Oleic acid and isopropyl myristate were purchased from Loba Chemie, India. The other chemicals were of analytical reagent grade.

\section{Methods}

\section{Selection of solid lipid ${ }^{13}$}

Solid lipid was selected by checking the solubility of the drug in melted lipid by means of visible observation with the naked eyes under normal light. Lipids used for this study were stearic acid, glyceryl mono stearate and cetyl palmitate. For this weighed quantity of the drug was taken separately with various lipids and then heated above the melting point of lipid in a temperature regulated water bath in $10 \mathrm{~mL}$ glass vials. After melting of lipid the solubility of Sertraline was in each lipid was observed visually under normal light.

\section{Selection of liquid lipid ${ }^{14}$}

Liquid lipid was selected based on the maximum solubility of the drug in different liquid lipids. Lipids used for this study were Isopropyl myristate, oleic acid. Excess amount of drug was taken in stopper vials containing $5 \mathrm{~g}$ of liquid lipids and mixing was carried out on a vortex mixer for $10 \mathrm{~min}$. Thereafter, vials were kept in an isothermal orbital shaker at $25 \pm 2.0^{\circ} \mathrm{C}$ for $24 \mathrm{~h}$ to reach equilibrium. Supernatant was separated by centrifugation at $5000 \mathrm{rpm}$ for $15 \mathrm{~min}$ and analyzed spectroscopically.

\section{Formulation of Sertraline loaded NLCs}

Formulation method was selected on the basis of ease of availability of equipments and materials which were used in the preparation of nanostructured lipid carriers.

\section{Emulsification- Solvent Evaporation}

In this method the hot lipid phase at $60^{\circ} \mathrm{C}$, containing $200 \mathrm{mg}$ of glyceryl monostearate, $0.05 \mathrm{~mL}$ of isopropyl myristate was dissolved in $10 \mathrm{~mL}$ a mixture of acetone and absolute ethanol. The oily phase was then dispersed in $50 \mathrm{~mL}$ aqueous phase containing $1 \%$ tween 80 at $50^{\circ} \mathrm{C}$ and stirred for $15 \mathrm{~min}$ at $4000 \mathrm{rpm}$. The resulting pre-emulsion was then ultrasonicated for $15 \mathrm{~min}$ using a probe sonicator at $50 \%$ amplitude to produce oil in water $(\mathrm{O} / \mathrm{W})$ nanoemulsion. In the final step, the obtained nanoemulsion $(\mathrm{O} / \mathrm{W})$ was cooled down at room temperature while stirring 600pm for about $1 \mathrm{~h}$.

\section{Design of experiment ${ }^{15,16}$}

A complete $3^{2}$ factorial design was utilized to study the effect of two independent variables namely solid lipid to liquid lipid concentration and stabilizer concentration on entrapment efficiency of the drug in prepared formulation. 2 variables and three levels are used for this study are depicted in Table 1 and the central composite experimental design for Sertarline loaded NLCs is given in Table 2.

Table 1: Variables and levels used in $3^{2}$ factorial designs for Sertraline loaded NLCs

\begin{tabular}{|l|l|l|l|}
\hline Factors & \multicolumn{3}{|l|}{ Levels } \\
\hline & $\mathbf{- 1}$ & $\mathbf{0}$ & $\mathbf{+ 1}$ \\
\hline $\mathbf{X}_{\mathbf{1}}$ & $225: 34$ & $200: 42$ & $175: 67$ \\
\hline $\mathbf{X}_{\mathbf{2}}$ & 0.5 & 1 & 1.5 \\
\hline
\end{tabular}

$\mathrm{X}_{1}=$ Solid: liquid lipid ratio $(\% \mathrm{w} / \mathrm{w}), \mathrm{X}_{2}=$ Concentration of stabilizer $(\%$ $\mathrm{w} / \mathrm{v})$.

Table 2: The central composite experimental design for Sertarline loaded NLCs.

\begin{tabular}{|l|l|l|l|}
\hline S. No. & Formulation code & $\mathbf{X}_{\mathbf{1}}$ & $\mathbf{X}_{\mathbf{2}}$ \\
\hline $\mathbf{1 .}$ & NLC-1 & -1 & -1 \\
\hline $\mathbf{2 .}$ & NLC-2 & -1 & 0 \\
\hline $\mathbf{3 .}$ & NLC-3 & -1 & +1 \\
\hline $\mathbf{4 .}$ & NLC-4 & 0 & -1 \\
\hline $\mathbf{5 .}$ & NLC-5 & 0 & 0 \\
\hline $\mathbf{6 .}$ & NLC-6 & 0 & +1 \\
\hline $\mathbf{7 .}$ & NLC-7 & +1 & -1 \\
\hline $\mathbf{8 .}$ & NLC-8 & +1 & 0 \\
\hline $\mathbf{9 .}$ & NLC-9 & +1 & +1 \\
\hline
\end{tabular}




\section{Preparation of NLCs}

NLCs loaded with Sertraline were developed using emulsification solvent diffusion and evaporation method with some modification. Drug was mixed in melted lipid phase (solid lipid and liquid lipid) and solvent mixture (ethanol: acetone). The mixture was heated on water bath to get clear organic solution then this solution was added into $50 \mathrm{~mL}$ of aqueous system containing Tween 80 as stabilizer kept on water bath maintained at $70^{\circ} \mathrm{C}$ under mechanical agitation of $6000 \mathrm{rpm}$ for $15 \mathrm{~min}$ using mechanical stirrer (Remi instrument Pvt Ltd, Mumabai, India.) then sonicated using probe sonicator for $15 \mathrm{~min}$ and then stirred again at $600 \mathrm{rpm}$ for $1 \mathrm{~h}$ to prevent the aggregation of nanoparticles. The prepared NLCs were lyophilized.

\section{Evaluation of Sertraline loaded NLCs}

\section{FTIR studies}

Drug-polymer interaction studies were conducted by Fourier transforms infrared (FTIR) spectroscopy. The spectra were recorded for Sertraline, Sertraline-glyceryl monostearate, and Sertraline-isopropyl myristate in a FTIR spectrophotometer (SHIMADZU, Japan) using $\mathrm{KBr}$ pellets at $400-4000 \mathrm{~cm}^{-1}$.

\section{Particle size and polydispersity index}

PDI is an index of width or spread or variation within the particle size distribution [17]. The size analysis and Polydispersity index of the nanoparticles were determined using a zeta sizer (Nano plus at BBAU, Lucknow.), each sample was suitably diluted with filtered distilled water (up to $2 \mathrm{~mL}$ ) in a cuvette. The Polydispersity index was studied to determine the narrowness of particle size distribution.

\section{Zeta potential}

The ZP, reflecting the electric charge on the particle surface and indicating the physical stability of colloidal systems, measured using a Zeta sizer after suitable dilution with distilled water.

\section{Drug loading and entrapment efficiency ${ }^{18,19}$}

The prepared NLC dispersion was centrifuged (SIGMA 318 K Refrigerated centrifuge Sartorius GERMANY) at $10000 \mathrm{rpm}$ at $10^{\circ} \mathrm{C}$ for $45 \mathrm{~min}$. The supernatant was separated and suitably diluted and the drug concentration was determined by UV spectroscopy (Shimadzu UV$1700)$ at $273 \mathrm{~nm}$. The percent of entrapment efficiency (\% EE) and drug loading (\% DL) was calculated according to following formula:

$$
\begin{gathered}
\% \mathrm{EE}=\frac{\mathrm{Wa}-\mathrm{Ws}_{\mathrm{s}}}{\mathrm{Wa}} \times 100 \\
\% \mathrm{DL}=\frac{\mathrm{Wa}-\mathrm{Ws}_{\mathrm{s}}}{\mathrm{Wa}-\mathrm{Ws}+\mathrm{WL}} \times 100 \\
\text { Where, Wa }=\text { Weight of drug added in system } \\
\mathrm{Ws}=\text { Analyzed weight of drug in supernatant } \\
\mathrm{W}_{\mathrm{L}}=\text { Weight of lipid added in system }
\end{gathered}
$$

\section{Surface morphology study}

Morphological characteristics of optimized formulation of NLCs were observed by SEM (scanning electron microscopy) at central instrumentation facility, IIT (BHU).

\section{In vitro drug release study}

The dissolution medium used was freshly prepared 7.4 phosphate buffer. Dialysis membrane, previously soaked overnight, was tied to one end of a specially designed glass cylinder (open at both ends). $5 \mathrm{~mL}$ of formulation was accurately placed into this assembly. The cylinder was attached to a stand and suspended in $100 \mathrm{~mL}$ of dissolution medium maintained at $37 \pm 5^{\circ} \mathrm{C}$ so that the membrane just touched the receptor medium surface. The dissolution medium was stirred at low speed using magnetic stirrer. An aliquot of $5 \mathrm{~mL}$ of the sample was withdrawn from the receiver compartment at predetermined time intervals and replenished with fresh medium. Samples were analyzed by UV-Visible spectrophotometer at a wavelength of $273 \mathrm{~nm}$. Drug release profile data of the optimized formulation was fitted to various mathematical models (zero- order, First order, Higuchi, Korsmeyer peppas) in order to describe the kinetics of drug release. Best goodness of fit test $\left(\mathrm{R}^{2}\right)$ was taken as criteria for selecting the most appropriate model.

\section{In-Vivo animal activity}

Forced swimming test (FST) ${ }^{20,21}$

The forced swimming test on chronic treated rats was performed to access the antidepressant effect of SRTNLCs. Adult male wistar rats weighing between 200 and $250 \mathrm{~g}$ were selected for the study. The protocol and procedures employed were ethically reviewed and approved by CPCSEA vide letter no. 1632/PO/Re/S/12/CPCSEA dated 13/11/2015 and the present study was approved by Institutional Animal Ethical Committee. Animals were divided in three groups with five animals in each group.

Group 1 was control group rats were kept as control and were administered saline solution (100 $\mu \mathrm{L}$ /day) $50 \mathrm{ml}$ in each nostril. Group 2 rats were administered Sertraline solution i. $\mathrm{n}$. at the dose of $0.486 \mathrm{mg} /$ day dissolved in 100 $\mathrm{ml}$ of normal saline solution. Group 3 rats were administered SRT - NLCs i.n. (1.08 mg/day equivalent to $0.486 \mathrm{mg} /$ day SRT) dispersed in $100 \mathrm{~mL}$ normal saline solution. The volume of nasal cavity of rats roughly varies from $150 \mathrm{~mm}^{3}$ to $250 \mathrm{~mm}^{3}$ which restricts the amount of drug formulation administered to about 100 to $150 \mathrm{~mL}$.

The intranasal doses were administered to rats without any anaesthesia or sedation. The doses were instilled with the help of micropipette $(200 \mu \mathrm{L})$ attached with the polyethylene tube having $0.1 \mathrm{~mm}$ internal diameter at the delivery site positioned $5 \mathrm{~mm}$ deep in each nostrils. The rats were held from the back in slanted position and were placed in supine posture during administration as well were held for approx 2 min after administration of doses. Rats were placed in a cylindrical tank $(40 \mathrm{~cm}$ tall, $20 \mathrm{~cm}$ in diameter) filled to a depth of $30 \mathrm{~cm}$ water $\left(25 \pm 2^{\circ} \mathrm{C}\right)$ individually for $15 \mathrm{~min}$ training and were then removed and dried. The water depth of $30 \mathrm{~cm}$ allowed the rats to swim or float without their hindlimbs or tails touching the bottom of the tank. The 6 min training was done $30 \mathrm{~min}$ after administration of dose in each group. After $24 \mathrm{~h}$ animals again were re-exposed to the swimming in a 
similar environment for $5 \mathrm{~min}$ and behavioural immobility time were recorded. For statistical comparison the standard and test group compared with the control group using GraphPad prism 5 software.

\section{Locomotor activity test (LAT)}

Digital photoactometer (instrument, India) equipped with infrared light sensitive photocells was used to determine the locomotor activity of all the five groups of animal used in FST. Eachanimal was observed in a closed square for $5 \mathrm{~min}$ using photoactometer. Locomotor activity was expressed in terms of total photobeam counts for $5 \mathrm{~min}$ per animal. The apparatus was placed in a standard darkened, light and sound attenuated, and ventilated testing room.

\section{Stability study}

The NLC dispersion was stored at room temperature (approximately $25^{\circ} \mathrm{C}$ ) and refrigerator temperature (approximately $4-10^{\circ} \mathrm{C}$ ) for one month and then analyzed for particle size, Polydispersity index and entrapment efficiency.

\section{RESULTS AND DISCUSSION}

\section{FTIR studies}

On the basis of IR spectrum analysis, it was found that, there was no interaction between drug and drug-polymer. The observed peak of sertraline observed at 3409.58, $1216.05,764.5 \mathrm{~cm}^{-1}$ as per established standards [22]. $\mathrm{NH}$ (stretch), $-\mathrm{CH}$ (stretch) and $-\mathrm{N}-\mathrm{CH}_{3}$ (bend) was found in the range where as in formulation with glyceryl monostrearate and isopropyl myristate, the vibrational frequency of $-\mathrm{N}-\mathrm{CH}_{3}$ (bend) at $1730.8 \mathrm{~cm}^{-1}$ over the range $\left(1670-1550 \mathrm{~cm}^{-1}\right)$ due to some hydrogen bonding with drug which is very weak (Fig. 1).

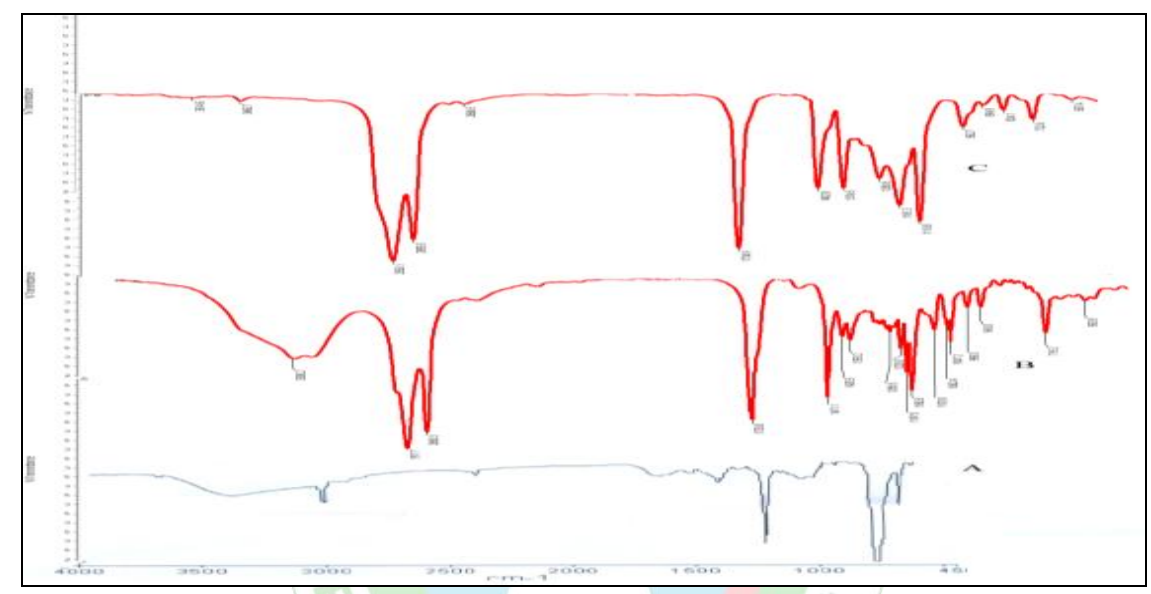

Figure 1: FTIR spectra of pure drug setraline, sertraline-glyceryl monostearate, and sertraline-isopropyl myristate

Overall the IR spectra indicate that no major change on vibrational frequency in dosage form.

\section{Physicochemical properties of NLCs}

Particle size measurement was required to confirm the production of the particles in nano-range. Particle size data for the nanostructured lipid carriers of sertraline. The mean particle size for formulationsNLC-1 to NLC-9 varied in range of 180 to $397.9 \mathrm{~nm}$ (Table 3).

Table 3: Particle size, particle dispersibility index zeta potential of various formulations

\begin{tabular}{|c|c|c|c|c|c|c|c|c|c|}
\hline $\begin{array}{l}\text { Sl. } \\
\text { No. }\end{array}$ & $\begin{array}{l}\text { Formulation } \\
\text { code }\end{array}$ & $\begin{array}{l}\text { Drug } \\
\text { conc. }\end{array}$ & $\begin{array}{l}\text { Lipid } \\
\text { conc. }\end{array}$ & $\begin{array}{l}\text { Surfactant } \\
\text { conc. }\end{array}$ & $\begin{array}{l}\text { Particle } \\
\text { size }\end{array}$ & PDI & $\begin{array}{l}\text { Zeta } \\
\text { Potential }\end{array}$ & $\% \mathbf{E E}$ & $\% \mathrm{DL}$ \\
\hline 1. & NLC-1 & 50 & $225: 34$ & 0.5 & 397.9 & 0.291 & -8.49 & 37.7 & 1.27 \\
\hline 2. & NLC-2 & 50 & $225: 34$ & 1 & 180.5 & 0.285 & -8.36 & 64.6 & 2.16 \\
\hline 3. & NLC-3 & 50 & $225: 34$ & 1.5 & 287.7 & 0.198 & -14.52 & 71.22 & 12.82 \\
\hline 4. & NLC-4 & 50 & $200: 42$ & 0.5 & 289.1 & 0.290 & -17.11 & 76.52 & 13.65 \\
\hline 5. & NLC-5 & 50 & $200: 42$ & 1.0 & 195.6 & 0.165 & -44.2 & 82.48 & 14.56 \\
\hline 6. & NLC-6 & 50 & $200: 42$ & 1.5 & 321.7 & 0.221 & +37.48 & 78.16 & 13.90 \\
\hline 7. & NLC-7 & 50 & $175: 67$ & 0.5 & 257.6 & 0.335 & -8.90 & 77.18 & 13.75 \\
\hline 8. & NLC-8 & 50 & $175: 67$ & 1.0 & 394 & 0.326 & -12.86 & 77.84 & 13.85 \\
\hline 9. & NLC-9 & 50 & $175: 67$ & 1.5 & 198.5 & 0.189 & -38.2 & 72.54 & 13.03 \\
\hline
\end{tabular}

The particle size analysis reveals that the size reduction was due to speed. As the lipid concentration was increased, more particles were aggregated resulting in an increased particle size. When the concentration of the lipid exceeded $2.5 \% \mathrm{w} / \mathrm{v}$ with a fixed concentration of surfactants, there was insufficient surfactant available to coat the surface of all the lipid droplets, resulting in particle aggregation and an increase in particle size.

Polydispersity index 
Polydispersity index (PI) indicates the width of the particle size distribution, which ranges from 0 to 1 . A monodisperse sample indicates PI value nearer to 0 .
However, PI $<1$ indicates polydisperse samples. Therefore, PI measurement was essential to confirm the size distribution of the particles as shown in Fig 2.

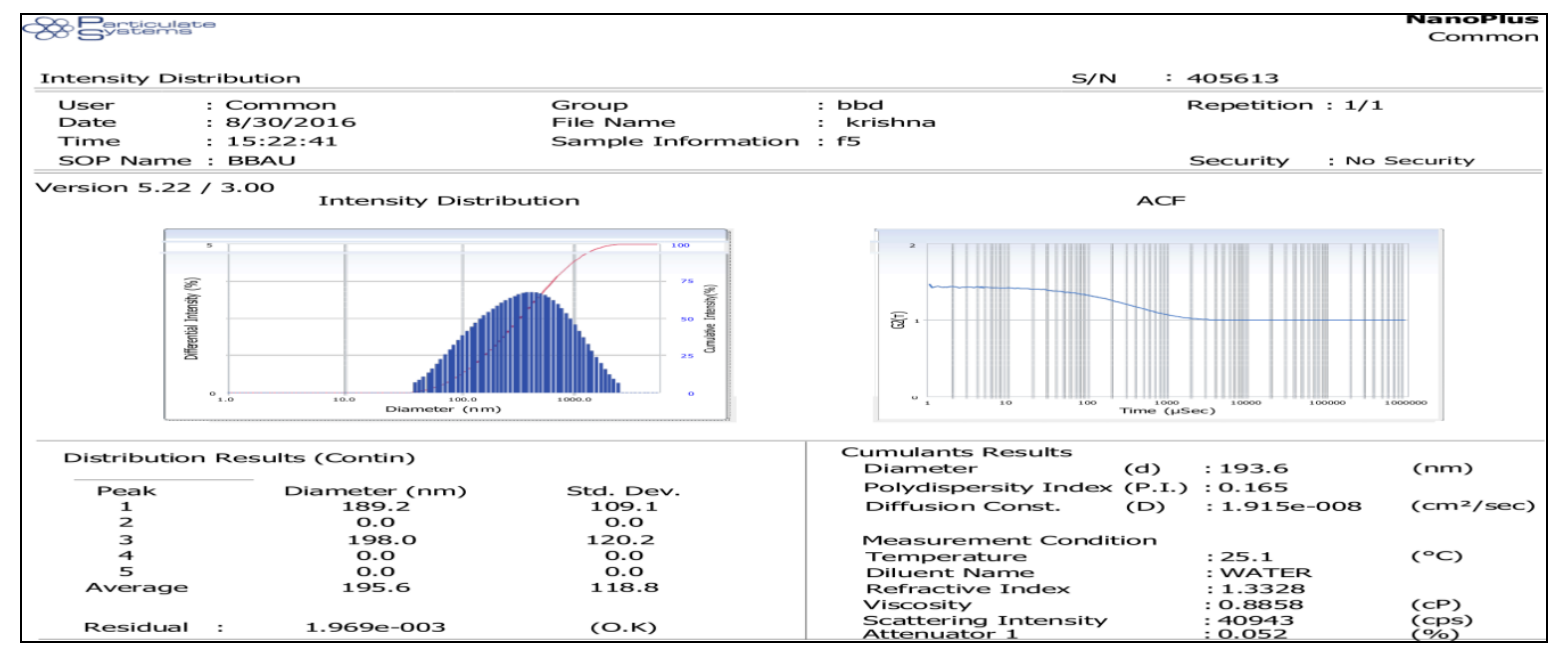

Figure 2: Particle size and polydispersity index of NLCs

The mean polydispersity index values for the drug loaded NLC formulations varied in the range of 0.198 to 0.355 . It could be inferred that all the formulations showed polydispersity.

\section{Zeta potential}

The ZP represents the electrical charge to the NLCs' surface. The greater the $\mathrm{ZP}$ value, the more likely the suspension is to be stable because the charged particles repel one another and thus overcome the natural tendency to aggregate (Fig 3).

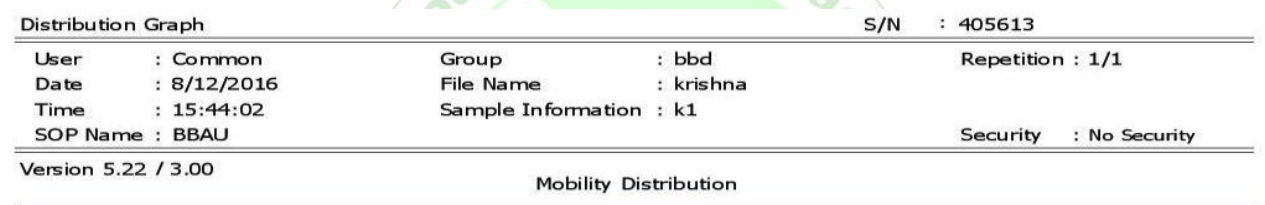

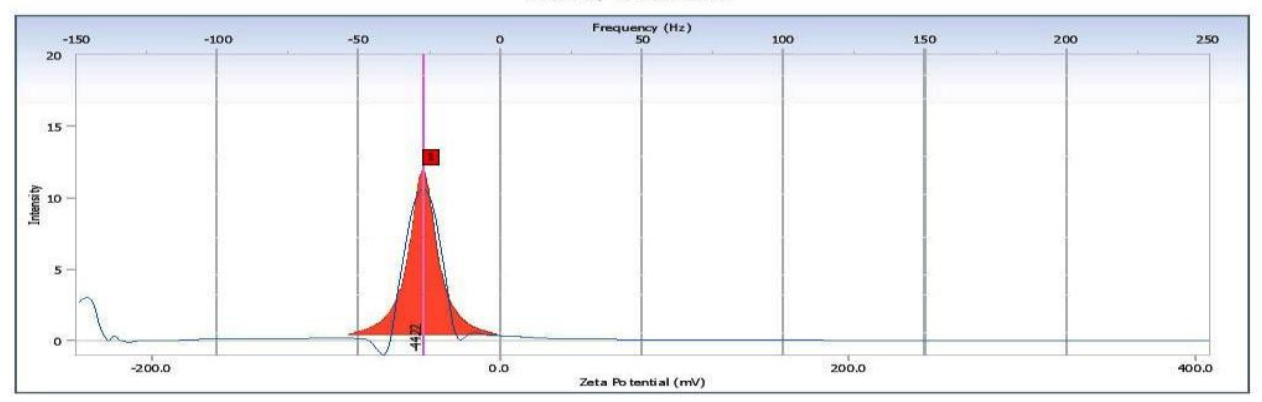

\begin{tabular}{|c|c|c|c|c|c|}
\hline & & Measuremen & t Results & & \\
\hline $\begin{array}{l}\text { Zeta Potential } \\
\text { Mobility } \\
\text { Conductivity }\end{array}$ & $\begin{array}{ll}: & -44.22 \\
: & -3.442 \mathrm{e}-004 \\
: & 0.0090\end{array}$ & $\begin{array}{l}(\mathrm{mV}) \\
(\mathrm{cm} / \mathrm{Ns}) \\
(\mathrm{ms} / \mathrm{cm})\end{array}$ & $\begin{array}{l}\text { Doppler shift } \\
\text { Base Frequency } \\
\text { Conversion Equation }\end{array}$ & $\begin{array}{ll}: & -27.14 \\
: & 122.9 \\
: & S m o l u c h o w s k i\end{array}$ & $\begin{array}{l}(\mathrm{Hz}) \\
(\mathrm{Hz})\end{array}$ \\
\hline $\begin{array}{l}\text { Zeta Potential of Cell } \\
\text { Upper Surface } \\
\text { Lower Surface } \\
\text { Cell Condition } \\
\text { Cell Type } \\
\text { Avg. Electric Field } \\
\text { Avg. Current }\end{array}$ & $\begin{array}{ll}: & 130.28 \\
: & 12.64 \\
: & \text { How Cell } \\
: & 16.39 \\
: & 0.01\end{array}$ & $\begin{array}{l}(\mathrm{V} / \mathrm{cm}) \\
(\mathrm{mA})\end{array}$ & $\begin{array}{l}\text { Diluent Properties } \\
\text { Diluent Name } \\
\text { Temperature } \\
\text { Refractive Index } \\
\text { Viscosity } \\
\text { Dielectric Constant }\end{array}$ & $\begin{array}{l}: \text { WATER } \\
: 24.9 \\
: 1.3328 \\
: 0.8898 \\
: 78.3\end{array}$ & $\begin{array}{l}\left({ }^{\circ} \mathrm{C}\right) \\
(\mathrm{CP})\end{array}$ \\
\hline \multicolumn{6}{|c|}{ Peak Data Table of Distribution Graph } \\
\hline $\begin{array}{ll}1 & -27.14 \\
2 & \end{array}$ & 11.90 & 5.29 & -44.22 & $-3.442 e-004$ & \\
\hline
\end{tabular}

Figure 3: Zeta potential of NLC

It is currently admitted that higher $\mathrm{ZP}$ values, either positively or negatively charged, mean that dispersion will have greater long-term stability. The $\mathrm{ZP}$ value was found to be -44.2 .

\section{Entrapment efficiency}

The experimental results indicate that the concentration of lipid has critical effect on the sertraline incorporation efficacy. The entrapment efficiencies of NLC made from different concentrations of lipid carrier are found be in the range of $79.5 \%$ to $89.06 \%$. The maximum entrapment efficiency $(89.06 \%)$ was found for 97.8 with $1 \%$ w/v surfactant concentration whereas it was less $(95.1 \%)$ for with $1 \% \mathrm{w} / \mathrm{v}$ lipid concentration. A higher concentration of lipid causes increase in the particle size that would affect the amount of Sertraline adsorbed on the surface of NLC. This is reasonable as higher amount of lipid was available to encapsulate drug molecules at higher lipid concentration. 


\section{Scanning electron microscopy}

The SEM image (Fig 4) of the optimized batch showed spherical particles of the size around $190.8 \mathrm{~nm}$ which is very near to the size necessary for brain delivery i.e. $200 \mathrm{~nm}$.

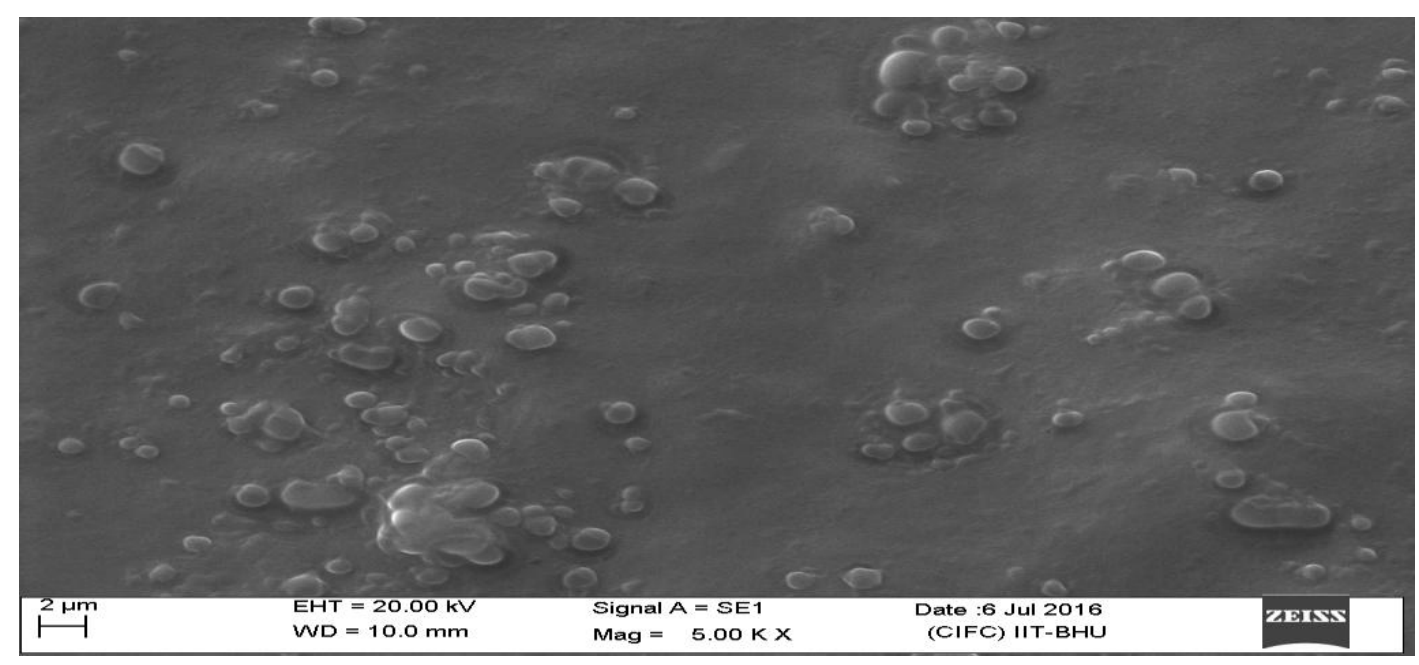

Figure 4: SEM image of NLC

The result was also supported by the non-significant difference with the measured particle size of optimized batch i.e. $195.6 \mathrm{~nm}$.

\section{In vitro drug release study}

In present study, the drug was entrapped in lipid matrix and thus lipid enhances the absorption and bioavailability of drug. In case of NLCs containing Sertraline the drug may be absorbed from the nasal epithelium. Thus NLCs broadens the absorption window and bioavailability of sertraline. Drug release was observed for $12 \mathrm{~h}$ in both buffer solutions. The \% CDR obtained in phosphate buffer $\mathrm{pH} 6.8$ was $79.35 \%$ (Table 4) and in vitro drug release study of various batches are shown in Fig 5 .

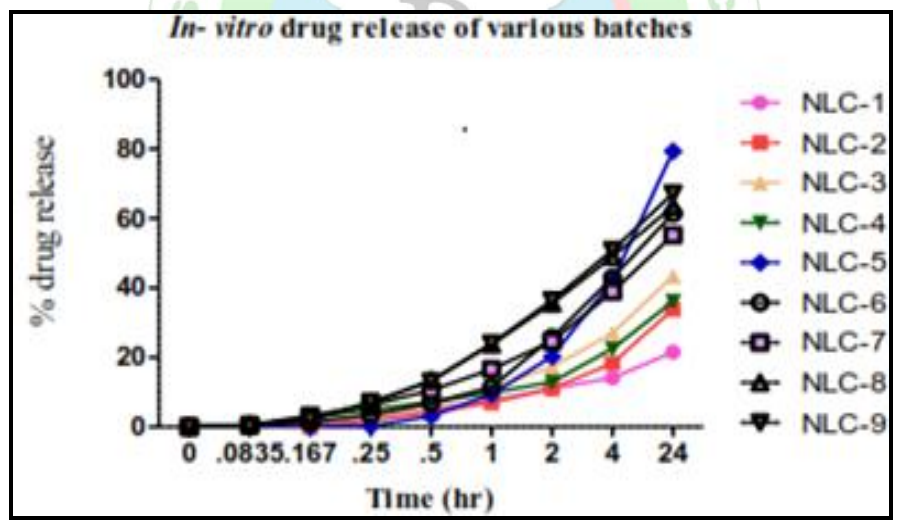

Figure 5: In vitro drug release of various batches

Table 4: In Vitro \% of drug release from various formulations

\begin{tabular}{|l|l|l|}
\hline Sl. No. & Formulation code & \% Drug release \\
\hline $\mathbf{1 .}$ & NLC-1 & $21.58 \%$ \\
\hline $\mathbf{2 .}$ & NLC-2 & $33.87 \%$ \\
\hline $\mathbf{3 .}$ & NLC-3 & $43.35 \%$ \\
\hline $\mathbf{4 .}$ & NLC-4 & $36.15 \%$ \\
\hline $\mathbf{5 .}$ & NLC-5 & $79.35 \%$ \\
\hline $\mathbf{6 .}$ & NLC-6 & $61.35 \%$ \\
\hline $\mathbf{7 .}$ & NLC-7 & $55.22 \%$ \\
\hline $\mathbf{8 .}$ & NLC- 8 & $49.06 \%$ \\
\hline $\mathbf{9 .}$ & NLC-9 & $67.2 \%$ \\
\hline
\end{tabular}


The regression coefficient $\mathrm{R}^{2}$ values determined are as given below (Table 5).

Table 5: Release kinetics study

\begin{tabular}{|l|l|l|l|l|}
\hline $\begin{array}{l}\text { Release } \\
\text { kinetics }\end{array}$ & $\begin{array}{l}\text { Zero order release } \\
\text { kinetics }\end{array}$ & $\begin{array}{l}\text { First order release } \\
\text { kinetics }\end{array}$ & $\begin{array}{l}\text { Higuchi release } \\
\text { kinetics }\end{array}$ & Korsmayer Pepppas release kinetics \\
\hline $\mathbf{R}^{2}$ & 0.8663 & 0.9662 & 0.9641 & 0.9297 \\
\hline
\end{tabular}

The $n(n>1)$ values derived from krosmeyer peppas equation suggests that the mechanism of release is super case II transport.

\section{Forced swim test (FST)}

The FST is a behavioural test commonly used to assess the efficiency of potential antidepressant drugs in rodents to predict the efficacy of antidepressant treatments in humans. The FST remains one of the most used tools for screening antidepressants. All parameters of pharmacodynamic tests were evaluated for their significance. The control group was found to differ significantly in all the four parameters compared to control $(\mathrm{P}<0.01)$.SRT-NLCs i.n. increased the total reduced the immobility more significantly $(\mathrm{P}<0.01)$ than depressed control It means that the SRT-NLCs i.n. restored the swimming time to the normal levels.

However the difference was highly significant $(\mathrm{P}<0.01)$ when compared with control animals (depressed animals) which proves the efficacy of the formulation.

\section{Locomotor activity test (LAT)}

The maximum locomotor counts were recorded for naive group and least for control group in SRT-NLCs i.n. treated groups shown significant increase in locomotor counts than the depressed control $(\mathrm{P}<0.01)$. The difference between the locomotor counts of SRT-NLCs i.n. treated group and control group was highly significant $(\mathrm{P}<0.01)$. The antidepressant activity of SRT-NLCs i.n. was greater than SRT i.n. which could be due to the maintenance of constant concentration of SRT in brain by SRT-NLCs.

\section{CONCLUSION}

The lipid nanoparticles NLCSs are carrier systems with good perspectives to be marketed very successfully. The reason for this is that they were developed by considering the industrial needs e.g. scale up, qualification and validation, simple technology, low cost etc. The stable Sertraline -NLCSs were successfully prepared by Emulsification solvent evaporation method and the nanosuspension was converted into dry powder by lyophilization. The Sertraline - NLCs showed improvement in rate of in-vitro drug release study. The improvement can be attributed to change in structure of lipid, reduced particle size, better, increased surface area. Thus NLCs suspension will be promising drug delivery system for improving the solubility and bioavailability by nose to brain delivery of Sertraline. These research findings strengthen the suitability of intranasal nose to brain drug delivery systems for brain targeting and treatment of the CNS disorders. These results also suggest that drugs could be transported by olfactory route to brain avoiding systemic circulation. The study however is in its infancy and it still requires significant clinical data on suitable higher animal models to evaluate its risk/benefit ratio and furthermore its efficacy in human.

\section{ACKNOWLEDGEMENT:}

All the authors are highly thankful to CIPLA Ltd., Sikkim, and India for providing sertraline as a gift sample.

\section{Source of funding: None}

Conflict of Interest statement: All the authors do here by declaring that there is no conflict of interest.

\section{REFERENCES:}

1. Bartha C, Parker C, Thomson C, Kitchen K. Centre for addiction and mental health depressive illness: A guide for people with depression and their families.1999;1-6.

2. Abrahamson DJ, Lynne M, Hornyak LM, Rehm LP. Understanding depression and effective treatment. American Psychological Association, 2010.

3. Gupta A, Aggarwal G, Singla S, Arora R. Transferosomes: A novel vesicular carrier for enhanced transdermal delivery of sertraline: Development, characterization, and performance evaluation. Scientia Pharmaceutica. 2012; 80(4):1061-1080.

4. Beloqui A, Solinís MA, Rodríguez-Gascón A, Almeida AJ, Préat V. Nanostructured lipid carriers: Promising drug delivery systems for future clinics Nanomedicine: Nanotechnology, Biology, and Medicine. 2016; 12(1): 143-161.

5. Patel KS, Solanki N, Solanki SN. Nanostructured lipid carrier- A novel drug delivery. Journal of Pharmaceutical Science and Bioscientific Research. 2015; 5(4):385-392.

6. Mishra DK, Kumar A, Raj R, Chaturvedi A. Capmul MCM based nanoemulsion for intranasal delivery of an antidepressant. Bulletin of Pharmaceutical Research. 2013; 3(1):34-39.

7. Gartziandia O, Herran E, Pedraz JL, Carro E, Igartua M, Hernandez RM. Chitosan coated nanostructured lipid carriers for brain delivery of proteins by intranasal administration. 2015; 134: 304-313.

8. Ammar HO, Ghorab MM, Mostafa DM, Ghoneim AM. Self-nano emulsifying drug delivery system for sertraline hydrochloride: design, preparation and characterization, International Journal of Pharmacy and Pharmaceutical Sciences. 2014; 6(9):589-595.

9. Rahman MA, Iqbal Z, Hussain A. Formulation optimization and in vitro characterization of sertraline loaded self-nanoemulsifying drug delivery system (SNEDDS) for oral administration. International Journal of Pharmaceutical Investigation. 2012; 42(4):191-202.

10. MacQueen G, Born L, Steiner M. The selective serotonin reuptake inhibitor sertraline: Its profile and use in psychiatric disorders. CNS Drug Reviews Vol. 7, No. 1, Neva Press, Branford, Connecticut: 2001; 7(1):1-24.

11. Alam MI, Baboota S, Ahuja A, Ali M, Ali J, Sahni JK, Bhatnagar A. Pharmacoscintigraphic evaluation of potential of lipid nanocarriers for nose-to-brain delivery of antidepressant drug. International Journal of Pharmaceutics.2014; 470(1-2):99-106.

12. Dandagi PM, Dessai GA, Gadad AP, Desai VB. Formulation and evaluation of nanostructured lipid carrier (NLC) of lornoxicam. International Journal of Pharmacy and Pharmaceutical Sciences. 2014; 6(2): 73-77.

13. Shah NV, Seth AK, Balaraman R, Aundhia CJ, Maheshwari RA, Parmar GR. Nanostructured lipid carriers for oral bioavailability enhancement of raloxifene: Design and In vivo study. Journal of Advanced Research. 2016; 7(3): 423-434. 
14. Gaba B, Fazil M, Khan S, Ali A, Baboota S, Ali J. Nanostructured lipid carrier system for topical delivery of terbinafine hydrochloride. Bulletin Faculty Pharmacy Cairo University. 2015; 53(2):147-159.

15. Eskandari S, Varshosaz J, Minaiyan M, Tabbakhian M. Brain delivery of valproic acid via intranasal administration of nanostructured lipid carriers: In vivo pharmacodynamic studies using rat electroshock model. International Journal of Nanomedicine.2011; 6:363-371.

16. Patel RJ, Patel ZP. Formulation optimization and evaluation of nanostructured lipid carriers containing valsartan. International Journal of Pharmaceutical Sciences and Nanotechnology. 2013; 6(2):2077-2086

17. Dandagi PM, Dessai GA, Gadad AP, Desai VB. Formulation and evaluation of nanostructured lipid carrier (NLC) of lornoxicam. International Journal of Pharmacy and Pharmaceutical Sciences.2014; 6(2):73-77.

18. Uner M, Karaman EF, Aydogmus Z. Solid lipid nanoparticles and nanostructured lipid carriers of loratadine for topical appliction:
Physicochemical stability and drug penetration through rat skin. Tropical Journal of Pharmaceutical Research. 2014; 13(5): 653-660.

19. Sethuraman N, Shanmuganathan S, Sandhya K, Anbarasan B. Design, development and characterization of nano structured lipid carrier for topical delivery of aceclofenac. Indian Journal of Pharmaceutical Education and Research. 2018; 52(4):581-586.

20. Patil NL, Mahajan HS. Quercetin loaded nanostructured lipid carriers for nose to brain delivery: In vitro and in vivo studies. Amercan Journal of Advanced Drug Delivery. 2018; 6(1):009-020.

21. Haque S, Md S, Sahni JK, Ali J, Baboota S. Development and evaluation of brain targeted intranasal alginate nanoparticles for treatment of depression. Journal of Psychiatric Research. 2014; 48(1):1-12

22. Moffat AC, Osselton MD, Widdop B. Clarke's analysis of drugs and poisons, Pharmaceutical Press, London (2011). 